Research Article

\title{
Changing pattern of prescribing antidiabetic agents in patients suffering from diabetes mellitus
}

\author{
Vipul P. Chaudhari ${ }^{\mathrm{a} *}$, Barna Ganguly ${ }^{\mathrm{b}}$
}

${ }^{a}$ Department of Pharmacology, G.C.S. Medical College, Ahmedabad - 380025, India, ${ }^{\mathrm{b}}$ Department of Pharmacology, Pramukh Swami Medical College, Karamsad, India

Received: 1 November 2012

Accepted: 19 November 2012

*Correspondence to:

Dr. Vipul P. Chaudhari, Email: drvip79@yahoo.co.in

\begin{abstract}
Background: Drug utilization studies are powerful exploratory tools to ascertain the role of drugs in society. They create a sound sociomedical and health economic basis for healthcare decision making. The study was aimed to find out the changing pattern of prescribing the antidiabetic agents in patients suffering from diabetes mellitus type 1 and 2 .

Methods: It was a cross sectional study done on 200 patients suffering from type 1 and 2 diabetes. Indoor patients and diabetes mellitus due to secondary cause were excluded. Each patient was followed up over a period of 1 year and the analysis of the prescriptions was done during that period. At end of study only 129 patients could be included for analysis.

Results: In this study the maximal change in medicine was with pioglitazone which was discontinued as a $1^{\text {st }}$ change in $6.2 \%$ of patients followed by metformin [5.4\%], insulin [4.6\%], and glipizide [3.8\%]. The drug most commonly added as a first change was glipizide [11.6\%] followed by metformin [10.0\%] and pioglitazone [7.7\%]. In order of $2^{\text {nd }}$ change the most common drug discontinued was insulin [4.6\%] followed by pioglitazone [3.8\%] whereas drug commonly added as second change was insulin [2.3\%] followed by glipizide [1.5\%] and pioglitazone [1.5\%]. In our cross sectional study average onset of $1^{\text {st }}$ change was found to be at $4.38 \pm 2.75$ months for discontinuation of drug and $3.75 \pm 2.42$ months in adding the drugs.

Conclusions: Due to lack of certain records, it is envisaged that the change of medicine both discontinuation as well as addition was done because of blood glucose control, cost factor [in case of pioglitazone] as well as patient's compliance.
\end{abstract}

Keywords: Antidiabetic agents, Prescriptions, Changing pattern

\section{INTRODUCTION}

Diabetes mellitus is a chronic disease, affecting nearly $6 \%$ of the world population. ${ }^{1}$ With changing life style in developing countries like India; diabetes mellitus has enormously increased the statistical figures. A survey depicts that $4 \%$ of the adults in India suffer from diabetes mellitus in the year 2000 and it is expected to increase to $6 \%$ by the year $2025 .^{2}$ In the developed world, the majority of diabetics are aged 65 years and above while in the developing world, the majority of diabetics are in the age group of 45-64 years. According to the Chennai Urban Population Study [CUPS] the prevalence of diabetes between the ages of 45 to 60 years was nearly $25 \%$, which was similar to that seen among individuals above the age of 65 years in developing countries. ${ }^{3}$ The management of type-1 diabetes mellitus depends mainly on insulin, whereas the management of type- 2 diabetes mellitus is mainly managed using oral hypoglycaemic agents (OHAs). ${ }^{4}$ Pharmacological therapy for diabetic patients is aimed at controlling hyperglycaemia to prevent or impede complications of diabetes mellitus. The results of the Diabetes Control and Complications Trial (DCCT) and the United Kingdom Prospective Diabetes Study (UKPDS) have showed that intensive diabetes mellitus management can reduce risk of complications. ${ }^{5,6}$ Therefore, appropriate drug therapy is necessary for diabetic patients to achieve adequate glycaemic control. Oral antidiabetic drugs (OADs) can be used either alone or in combination with other OADs or insulin (IN). In the past few years, several new OADs have been added to the therapeutic armamentarium in 
India. Before 1996, only Insulin, sulphonylureas (SUs), and biguanides (BGs) as well as an adjunctive drug, guar gum was available for the treatment of type 2 DM. After 1996, many new OADs have become available to clinicians and type 2 diabetic patients, for use both as monotherapy and in combination therapy. The newer agents include an alpha-glucosidase inhibitor (AGI) acarbose, released in 1996; the newest Sulphonylurea glimepiride released in 2000; two rapid acting non-SU secretagogues or meglitinides (MGs), repaglinide and nateglinide, released in 2000 and 2002, respectively; and two thiazolidinediones (TZDs), rosiglitazone and pioglitazone released in 2001 and 2002, respectively. ${ }^{7}$ Diabetes mellitus, if uncontrolled, leads to several acute and chronic complications. ${ }^{8}$ The chronic complications of diabetes mellitus make it necessary to prescribe drugs for these patients life long. Moreover, a good number of diabetes patients suffer from cardiovascular disease such as hypertension, hyperlipidaemia and ischaemic heart disease. ${ }^{9}$ This further necessitates polypharmacy in these patients. A study from the United States of America (USA) reported that about 1.3 million adults with disabilities did not take their medications as prescribed because of cost, and as a result, more than half reported health problems. ${ }^{10}$ Drug utilization studies are powerful exploratory tools to ascertain the role of drugs in society. They create a sound sociomedical and health economic basis for healthcare decision making. ${ }^{11}$ With a reported burden of 32-35 million diabetics ${ }^{12}$ in India, and lack of study on drug changing pattern in Gujarat; this study was carried out with the aim of finding out the changing pattern of prescribing the antidiabetic agents in patients suffering from diabetes mellitus type 1 and 2 . The data thus obtained would give feedback to clinicians and form a baseline for future study with additional parameters for analysis.

\section{METHODS}

The department of Medicine in Shree Krishna Hospital runs a specialized diabetic clinic providing outpatient services with laboratory facilities. Prior approval was taken from institutional human research ethics committee. Cross sectional study was done and total 200 patients attending outpatient department in medicine were recruited within the period of 4 months and each patient was followed up for 1 year. Detail data on prescribed drug/drugs for each patient was taken every 2 months. Inclusion criteria refers to recruitment of Patients of both sexes primarily suffering from diabetes mellitus aged above 18 years of both type 1 and type 2 attending outpatient department of Shree Krishna Hospital whereas exclusion criteria refers to Indoor patients, diabetes due to some secondary cause, pediatric patients and history of liver and renal disorder since last 6 months. Before analyzing any patient's prescription for this study, he/she was explained the aspects of research work. Patient's consent was taken before including him or her into the study. Once the consultation by the physician was over, the detailed information written in the case record were noted and the patients were interviewed. On the first visit, history of patient was taken with special reference to history of drug intake and allergy. Each patient was followed up for 1 year. On subsequent visits each patient was inquired of any change in the drug, addition of different drug, change in dosage and frequency of the drug.

\section{RESULTS}

At end of study only 129 patients could be included for analysis and remaining were lost to follow up. Out of various antidiabetic agents, the most common drug prescribed in 1 year study was metformin in $37.1 \%$ [ $n=101]$ patients, followed by glipizide in $29.7 \%$ [ $n=81]$ patients, insulin was prescribed in $11.3 \%$ [ $n=31]$ patients, glimepiride in $8.0 \%$ [ $n=22]$ patients, and pioglitazone in $8.8 \%[n=24]$ patients. Only $2.9 \%[n=8]$ patients took glibenclamide, $1.0 \%[n=3]$ patients took repaglinide and gliclazide was given in $0.7 \%[n=2]$ patients. In 1 year follow up study it was found that the drug that was maximally discontinued as a first change was pioglitazone [6.2\%] followed by metformin [5.4\%], insulin [4.6\%], and glipizide [3.8\%]. Similarly the drug added maximally as a first change was glipizide [11.6\%] followed by metformin [10.0\%] and pioglitazone [7.7\%] (Table 1).

Table 1: $1^{\text {st }}$ change of drugs in prescribing pattern.

\begin{tabular}{|lll|}
\hline Drugs & \multicolumn{2}{l|}{ No. of patients } \\
\hline & Discontinued & \multicolumn{1}{c|}{ Added } \\
\hline Insulin & $6[4.6 \%]$ & $4[3.1 \%]$ \\
\hline Glipizide & $5[3.8 \%]$ & $15[11.6 \%]$ \\
\hline Glimepiride & $2[1.5 \%]$ & $3[2.3 \%]$ \\
\hline Glibenclamide & $1[0.7 \%]$ & 0 \\
\hline Metformin & $7[5.4 \%]$ & $13[10.0 \%]$ \\
\hline Repaglinide & $2[1.5 \%]$ & $1[0.7 \%]$ \\
\hline Pioglitazone & $8[6.2 \%]$ & $10[7.7 \%]$ \\
\hline
\end{tabular}

In $2^{\text {nd }}$ change, it was insulin [4.6\%] which was most commonly discontinued; pioglitazone [3.8\%] was next. In added group it was insulin [2.3\%] most commonly added as second change followed by glipizide [1.5\%] and pioglitazone [1.5\%] (Table 2). 
Table 2: $2^{\text {nd }}$ change of drugs in prescribing pattern.

\begin{tabular}{|lll|}
\hline \multicolumn{1}{|c|}{ Drugs } & No. of patients & \\
& Discontinued & Added \\
\hline Insulin & $6[4.6 \%]$ & $3[2.3 \%]$ \\
\hline Glipizide & $1[0.7 \%]$ & $2[1.5 \%]$ \\
\hline Glimepiride & $2[1.5 \%]$ & 0 \\
\hline Glibenclamide & 0 & $1[0.7 \%]$ \\
\hline Metformin & $4[3.1 \%]$ & $1[0.7 \%]$ \\
\hline Pioglitazone & $5[3.8 \%]$ & $2[1.5 \%]$ \\
\hline
\end{tabular}

The drugs mostly discontinued and added were within initial 5 months with mean \pm SD of $4.38 \pm 2.75$ months and 3.78 \pm 2.42 months respectively. Whereas second change occurred throughout the year without predominance of any single month. The mean \pm SD for discontinued and added drug was $6.61 \pm 3.18$ month and $6.77 \pm 3.83$ months respectively (Table 3 ).

Table 3: Months at which the drugs were discontinued or added.

\begin{tabular}{|c|c|c|c|c|c|}
\hline \multicolumn{3}{|c|}{$1^{\text {st }}$ Change } & \multicolumn{3}{|c|}{$2^{\text {nd }}$ Change } \\
\hline Month & $\begin{array}{l}\text { Drug discontinued in } \\
\text { patients }\end{array}$ & $\begin{array}{l}\text { Drug added in } \\
\text { Patients }\end{array}$ & Month & $\begin{array}{l}\text { Drug discontinued in } \\
\text { patients }\end{array}$ & $\begin{array}{l}\text { Drug added in } \\
\text { Patients }\end{array}$ \\
\hline 1 & 3 & 5 & 1 & - & - \\
\hline 2 & 6 & 12 & 2 & 2 & 2 \\
\hline 3 & 4 & 9 & 3 & 2 & 1 \\
\hline 4 & 8 & 7 & 4 & 1 & - \\
\hline 5 & - & 4 & 5 & 3 & - \\
\hline 6 & 5 & 2 & 6 & 2 & 1 \\
\hline 7 & - & 4 & 7 & - & 1 \\
\hline 8 & 2 & 1 & 8 & 1 & 1 \\
\hline 9 & 1 & - & 9 & 3 & - \\
\hline 10 & 1 & 1 & 10 & 1 & 1 \\
\hline 11 & - & - & 11 & 3 & 1 \\
\hline 12 & 1 & 1 & 12 & - & 1 \\
\hline $\begin{array}{l}\text { Mean } \pm \text { SD } \\
\text { for months }\end{array}$ & $4.38 \pm 2.75$ & $3.78 \pm 2.42$ & & $6.61 \pm 3.18$ & $6.77 \pm 3.83$ \\
\hline
\end{tabular}

Thereafter as third change insulin [1.5\%], glipizide [0.7\%] and metformin [0.7\%] were commonly added (Table 4).

Table 4: $3^{\text {rd }}$ change of drugs in prescribing pattern.

\begin{tabular}{|lcl|}
\hline Drugs & No. of patients & \\
\hline & Discontinued & Added \\
\hline Insulin & 0 & $2[1.5 \%]$ \\
\hline Glipizide & 0 & $1[0.7 \%]$ \\
\hline Glimepiride & 0 & 0 \\
\hline Metformin & 0 & $1[0.7 \%]$ \\
\hline Pioglitazone & 0 & 0 \\
\hline
\end{tabular}

Only one patient had fourth change and it was glipizide which was discontinued (Table 5).

Table 5: $4^{\text {th }}$ change of drugs in prescribing pattern.

\begin{tabular}{|c|c|c|}
\hline Drugs & No. of patient & \\
\hline & Discontinued & Added \\
\hline Glipizide & $1[0.7 \%]$ & 0 \\
\hline
\end{tabular}

\section{DISCUSSION}

Diabetes is a chronic disease requiring lifelong treatment. Although lifestyle modifications play an important role in diabetes management, drugs become unavoidable in many patients. This study analysed the changing pattern in 
diabetic patients attending out-patient departments in a Shree Krishna Hospital, Karamsad. In one year study period most common drug discontinued as a first change was pioglitazone [6.2\%] followed by metformin [5.4\%], insulin [4.6\%] and glipizide [3.8\%]. The reason for discontinuation can be either poor control of diabetes, noncompliance, higher cost or unreported adverse drug reaction of particular drug. The mean time of discontinuation was $4.38 \pm 2.75$ months [131.4 \pm 82.5 days]. This was higher than the study done in America [83 \pm 71 days] which also mention that discontinuation increase with increase in duration of treatment. ${ }^{13}$ This was difficult to prove in this study due to limited time period. The delay in discontinuation in this study can be either due to good control of diabetes or better compliance of drug. Concomitant antidiabetic agent was started in some patients and the most common drug added as first change was glipizide [11.6\%], followed by metformin [10.0\%] and pioglitazone [7.7\%]. The addition of drug can be due to poor control of diabetes and synergistic effect of particular drug with previous drug. The mean duration of addition was $3.78 \pm 2.42$ months [113.4 \pm 72.6 days]. The American study showed the mean time $129 \pm 108$ days which is near to this finding. Subsequently the most common drug discontinued as second change was insulin [4.6\%] and most common drug added as second change was also insulin [2.3\%]. This may be because insulin is added in type 2 diabetes patients when their blood glucose is not controlled with oral hypoglycaemic and when glycemic control is stabilised patients are switched back to oral hypoglycaemic drugs.

Due to lack of certain records, it is envisaged that the change of medicine both discontinuation as well as addition was done because of blood glucose control, cost factor [in case of pioglitazone] as well as patient's compliance.

Funding: No funding sources

Competing interests: None declared

Ethical approval: Approval was taken from the institutional human research ethics committee

\section{REFERENCES}

1. Mayor S. Diabetes affects nearly $6 \%$ of the world's adults. BMJ 2006;333:1191.

2. King H, Aubert RE, Herman WH. Global burden of diabetes, 1995-2025: prevalence, numerical estimates and projections. Diabetes Care 1998;21:1414-31.

3. Mohan V, Madan Z, Jha R, Deepa R, Pradeepa R. Diabetes-Social and Economic Perspectives in the New Millennium. Int $\mathbf{J}$ Diab Dev Countries 2004;24:29-35.

4. Cantrill JA, Wood J. Diabetes mellitus. In: Walker $\mathrm{R}$, Edwards C, editors. Clinical pharmacology and therapeutic. 3rd ed. New York: Churchill Livingstone 2003;657-77.

5. The Diabetes Control and Complications Trial Research Group .The effect of intensive treatment of diabetes on the development and progression of long-term complications in insulin-dependent diabetes mellitus. N Engl J Med 1993;329:977-86.

6. UK Prospective Diabetes Study Group. Intensive blood glucose control with sulphonylureas or insulin compared with conventional treatment and risk of complications in patients with type 2 diabetes (UKPDS 33). Lancet 1998;352:837-53.

7. Bureau of National Health Insurance (2004). Drug reimbursement price and date approved by Bureau of National Health Insurance. Available at: http://www.nhi.gov.tw/06inquire/query1.asp.

Accessed 20 June 2007.

8. Powers AC. Diabetes mellitus. In: Braunwald E, Fauci AS, Kasper DL, Hauser SL, Longo DL, Jameson JL, editors. Harrison's principles of internal medicines. 15th ed. New York: McGrawHill Inc 2001:2109-37.

9. Triplitt CL, Reasner CA, Isley WL. Diabetes mellitus. In: Dipiro JT, Talbert RL, Yee GC, Matzke GR, Wells BG, Posey LM, editors. Pharmacotherapy: a pathological approach. $6^{\text {th }}$ ed. New York: McGraw-Hill Inc 2005:1333.

10. Kennedy J, Erb C. Prescription noncompliance due to cost among adults with disabilities in the United States. Am J Public Health 2002;92:1120-4.

11. Bakssas I, Lunde PKM. National drug policies: the need for drug utilization studies. Trends Pharmacol Sci 1986;7:331-4.

12. Press Trust of India. Insulin to cost less. The Hindu 2003 Jan 4; p.13. (Col.1).

13. Boccuzzi S J, Wogen J, Fox J, Sung JCY, Shah AB, Kim J. Utilization of oral hypoglycemic agents in a drug-insured US population. Diabetes Care 2001;24:1411-5.

doi:10.5455/2319-2003.ijbcp20130109

Cite this article as: Chaudhari VP, Ganguly B.

Changing pattern of prescribing antidiabetic agents in patients suffering from diabetes mellitus. Int J Basic Clin Pharmacol 2013;2:47-50. 